\title{
International Journal of Quantitative Research and
} Modeling

Vol. 2, No. 1, pp. 1-10, 2021

\section{Shelf Life of Nori from Gracilaria Sp. With Alumunium Foil Packaging Based on The Accelerated Shelf Life Test Method}

\author{
Evi Liviawaty ${ }^{1, *}$, Sapinatun Namira ${ }^{1}$, Subiyanto $^{2}$, Eddy Afrianto ${ }^{1}$ \\ ${ }^{1}$ Department of Fishery, Faculty of Fishery and Marine Science, Universitas Padjadjaran, Jatinangor, Indonesia \\ ${ }^{2}$ Department of Marine Science, Faculty of Fishery and Marine Science, Universitas Padjadjaran, Jatinangor, Indonesia
}

*Corresponding author email: evi.liviawaty@unpad.ac.id

\begin{abstract}
This research was conducted at the Laboratory of Fisheries Products Processing, Faculty of Fisheries and Marine Sciences, Universitas Padjadjaran, Jatinangor. The purpose of this research is to determine the shelf life of Nori from Gracilaria sp. with the Accelerated Shelf Life Test (ASLT) method Arrhenius Model using Aluminum Foil packaging. Aluminum foil packaging is a package composed of hermetic, flexible, and opaque metal so that it has high protection properties against water vapor, light, grease and gas. The determination of the shelf life of the ASLT method is carried out using parameters of environmental conditions that can accelerate the process of product quality degradation, namely by storing the product at several temperatures above normal storage temperature. The observations used in determining the shelf life of Gracilaria sp. using a sensory test and a water content test with storage for 35 days, at a temperature of $25 \mathrm{oC}$ and $35 \mathrm{oC}$. The result of the Arrhenius model calculation, the appearance parameter is selected as the critical parameter because it has the lowest Activation Energy (Ea) in determining the shelf life of Gracilaria sp. which is packaged using PE plastic. The results show that the parameters used to determine the shelf life of the product are the taste parameters based on the order 1 reaction with the Arrhenius Plot Ln K $=0.026-1318.4(1 / \mathrm{T})$ and Ea of $2619.66 \mathrm{Kj} / \mathrm{mol}$. The shelf life of Nori Gracilaria sp. if stored at $25 \mathrm{oC}$ temperature is 89 days 7 hours.
\end{abstract}

Keywords: Aluminum foil, Arrhenius, ASLT, Gracilaria sp., nori, shelf life

\section{Introduction}

Japanese food has become a lifestyle for several people in Indonesia. One of the favorite Japanese foods is sushi. Sushi is a food filling consisting of rice, watercress, seafood, kyuri and then rolled coated using dried seaweed sheets or what we usually know as nori. Nori is the main ingredient in sushi making. Nori is the name in Japanese for food in the form of dried seaweed sheets (Abduh, Maulana, Tinggi \& Trisakti, 2018).

Seaweed is one of the marine plants belonging to the benthic macroalgae that lives attached to the bottom of the waters (McHugh, 2003). According to the Indonesian Seaweed Association (ARLI), of the 555 types of seaweed found in Indonesia, only 3 types can only be cultivated, including Gracilaria, Eucheuma Cotonii, and Eucheuma Spinosum. One of the seaweed species. important economic value in Indonesia, namely Gracilaria sp. from the Rhodophyceae class, this seaweed is widely used as raw material for making agar (Supriyantini, Santosa \& Alamanda, 2018).

Gracilaria sp. widely used in the industrial sector, one of which is the food and beverage industry such as ice cream, cheese, candy, jelly, and chocolate milk, as well as fish and meat canning (Suparmi \& Sahri, 2009). Apart from these preparations, one of the efforts to utilize the resources of Gracilaria sp. another is by processing it into nori products (Teddy, 2009). Nori Gracilaria sp. is a new processed seaweed product, so it is necessary to know the nutritional content and shelf life of the product. One way to maintain and extend the shelf life of a product is by using packaging. Packaging can protect food that has been produced either in packaging or placing the product into a container (Sucipta, Suriasih \& Kenacana, 2017).

Aluminum foil packaging has good water and gas molecular migration barrier properties (Hendrasty, 2013), making it suitable for packaging nori which has dry characteristics and easily becomes moist so that its quality is maintained. Aluminum foil packaging is composed of hermetic, flexible, and opaque metal so that it has high protective properties against water vapor, light, grease and gas (Aprida, 2017).

The Arrhenius model of Accelerated Shelf Life Test (ASLT) method is a method of estimating the shelf life of a product by using an acceleration temperature so that it can accelerate the reaction that causes damage to the product (Herawati, 2008). This method is generally applied to all types of food products, especially those that have decreased 
quality due to the effects of chemical deterioration (Arpah, 2001). Based on this background, research is needed to determine the shelf life of Nori products made from Gracilaria sp. with the Accelerated Shelf Life Test (ASLT) method Arrhenius model.

\section{Material and Method}

\subsection{Tools and Material}

The tools used in this research are a basin, blender, baking sheet $(15 \times 20 \mathrm{~cm})$, scale, oven, measuring cup, spoon, pan, label, Aluminum foil (0.6 mm thickness), incubator and sealer. The materials used in this research are dried seaweed (Gracilaria sp.), rice water, clean water, salt, sugar and ground pepper, flavorings, sesame oil, olive oil and fish sauce.

\subsection{Method}

This research uses the ASLT method Arrhenius model using nori products made from Gracilaria sp. packed into aluminum foil packaging. The packaged products are stored at $25 \mathrm{oC}$ and $35 \mathrm{oC}$ as a determination of acceleration temperature. Observations were made on days 1, 7, 14,21, 28 and 35. The parameters tested for estimating the shelf life of the Arrhenius model ASLT method were using water content test data and sensory evaluation (appearance, aroma, texture, taste) tested by the standard panelist.

\subsection{Data Analysis}

Nori from Gracilaria sp. determined based on the value of the smallest activation energy. Ea (activation energy) can provide an idea of the magnitude of the effect of temperature on the reaction. The formula for determining shelf life is as follows:

If you follow the zero-order kinetics rate model the formula is as follows:

$$
C_{t}-C_{0}=K t
$$

Furthermore, if the reaction rate follows order one the formula is as follows:

$$
\ln C_{t}=\ln C_{0}+K t
$$

\section{Results and Discussion}

\subsection{Organoleptic Characteristics of Nori Gracilaria sp.}

\subsubsection{Appearance}

Appearance assessment aims to determine the panelists' acceptance as assessed from the surface appearance and nori color made from Gracilaria sp. Product appearance is the most important attribute in a product. In choosing a product, consumers will consider the appearance of the product first and ignore other sensory attributes (Tarwendah, 2017). The level of acceptance of food products from appearance can be influenced by color changes, this is because color changes can indicate changes in nutritional value, so that color changes are used as indicators of quality degradation (Hasany, Afrianto \& Pratama, 2017).

Table 1: Average Value of the Appearance Parameters of Nori from Gracilaria sp.

\begin{tabular}{ccc}
\hline \multirow{2}{*}{ Day Storage To- } & \multicolumn{2}{c}{ Appearance Parameters } \\
\cline { 2 - 3 } & $\mathbf{2 5}^{\circ} \mathbf{C}$ & $\mathbf{3 5}^{\mathbf{}} \mathbf{C}$ \\
\hline 1 & 8.43 & 8.43 \\
7 & 8.14 & 8.14 \\
14 & 7.86 & 7.57 \\
21 & 7.57 & 7.29 \\
28 & 6.71 & 6.43 \\
35 & 6.43 & 6.14 \\
\hline
\end{tabular}

The average value of the appearance parameters of nori made from Gracilaria sp. (Table 1) which is packaged using aluminum foil shows a decrease in appearance quality along with the length of the storage period both at $25 \mathrm{oC}$ and $35 \mathrm{oC}$. The high and low average appearance values are influenced by several factors including pigments, caramelization 
reactions, Maillard reactions (reactions between amino groups and reducing sugar groups), reactions of organic compounds with air and the addition of dyes (Winarno, 2004).

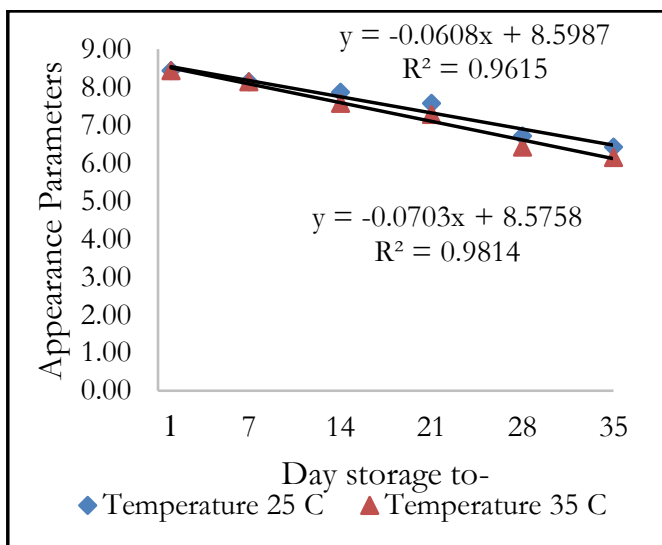

a. Order 0

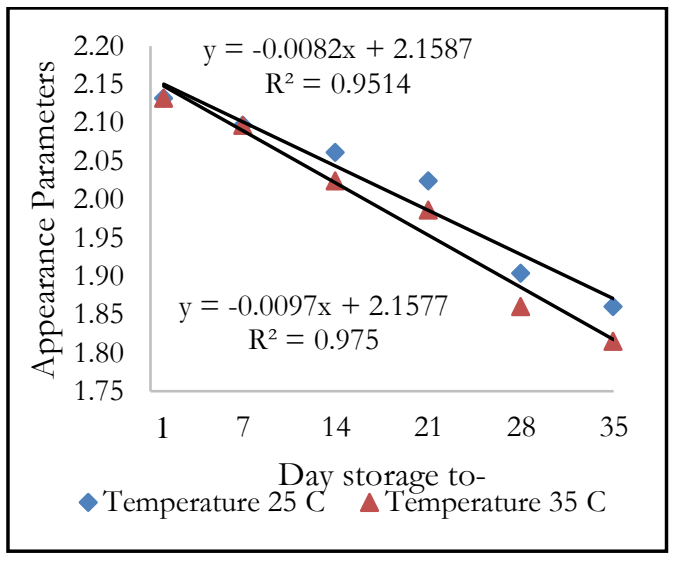

b. Order 1

Figure 1: Graph of the Decrease in Appearance Value Against Time

The value of R2 for both temperature order $0(0.9814)$ is greater than order $1(0.975)$ in the graph of the decrease in the appearance score against time, so order 0 is selected to determine the Arrhenius plot.

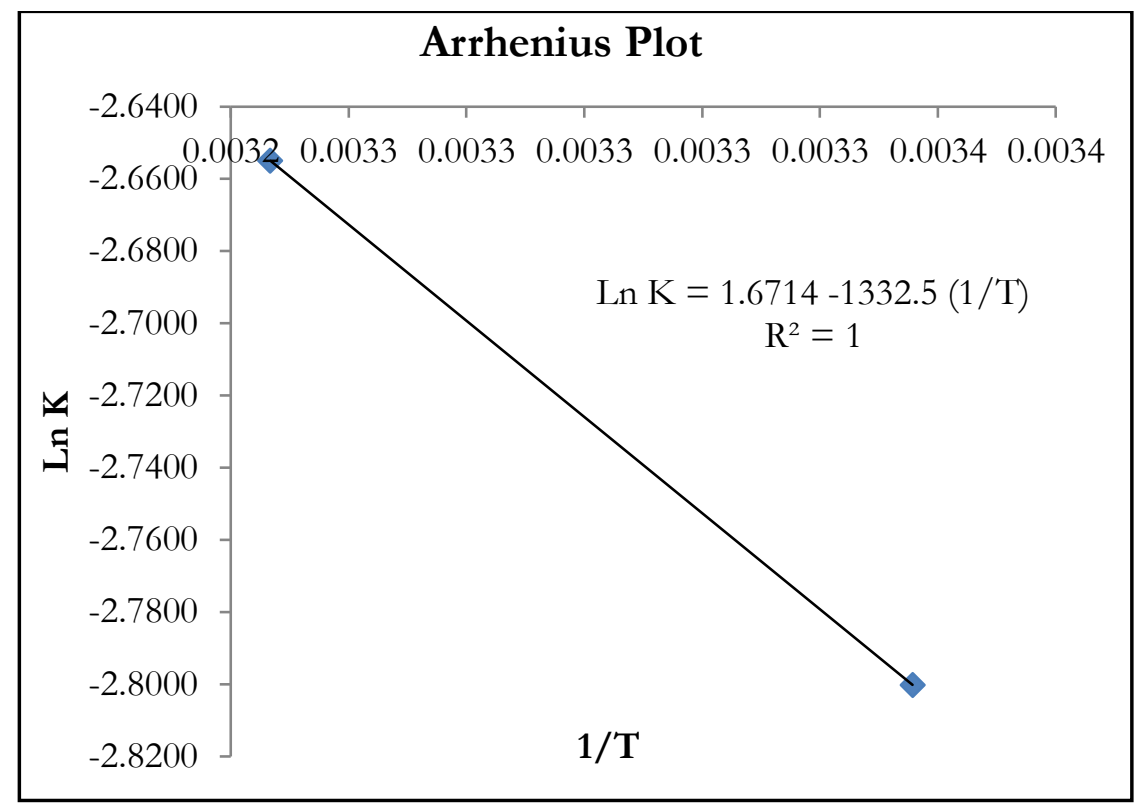

Figure 2: Graph of Arrhenius Plot Parameters Appearance of Nori Gracilaria sp.

Based on the graph of the Arrhenius plot, the appearance parameter (Figure 2), the slope value is obtained which is a linear amalgamation of the two temperatures used in Nori storage made from Gracilaria sp. The results of linear regression analysis of the $1 / \mathrm{T}$ and $\mathrm{Ln} \mathrm{K}$ plots on the decrease in the appearance produce the plot Ln $\mathrm{K}=1.6714-1332.5$ $(1 / \mathrm{T})$.

\subsubsection{Aroma}

Aroma or odor can be produced due to the presence of volatile compounds (volatile) in food and will be carried by air and enter the nasal cavity (DeMan, 1997). Aromatic compounds are volatile, so they easily reach the olfactory system at the top of the nose, and need sufficient concentration to interact with one or more olfactory receptors (Tarwendah, 2017). The aroma parameter determines consumer acceptance because aroma or odor stimuli become impulses that will go to the olfactory nerve and describe the characteristics of a product (Hasany, Afrianto \& Pratama, 2017).

Table 2: Average Value of the Aroma Parameters of Nori from Gracilaria sp. 


\begin{tabular}{ccc}
\hline 1 & 8.14 & 8.14 \\
7 & 8.14 & 7.57 \\
14 & 7.57 & 7.00 \\
21 & 7.29 & 6.71 \\
28 & 6.43 & 5.86 \\
35 & 5.86 & 5.00 \\
\hline
\end{tabular}

The Average Value of the Appearance Parameters of nori made from Gracilaria sp. (Table 2) which is packaged using aluminum foil shows a decrease in the quality of the aroma along with the length of the storage period both at $25 \mathrm{oC}$ and $35 \mathrm{oC}$. The quality degradation is caused by the evaporation process of volatile compounds in nori made from Gracilaria sp. The longer the storage time and temperature, the greater the evaporation rate of volatile compounds in the product (Majid, Agustini \& Rianingsih, 2014).

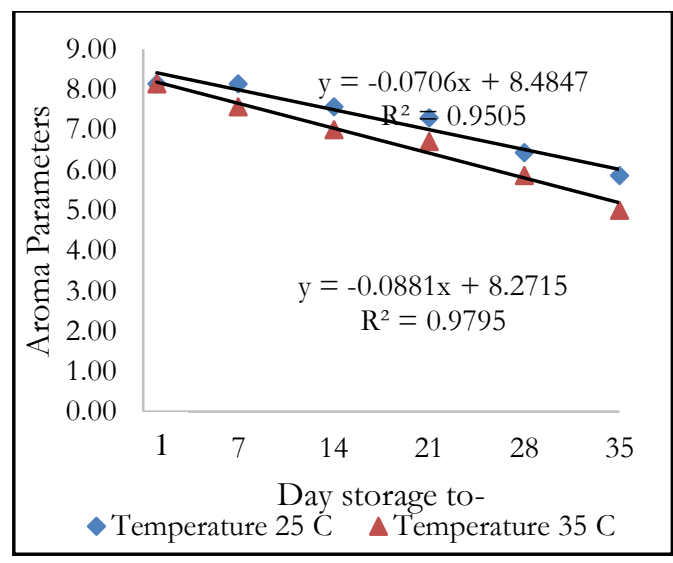

a. Order 0

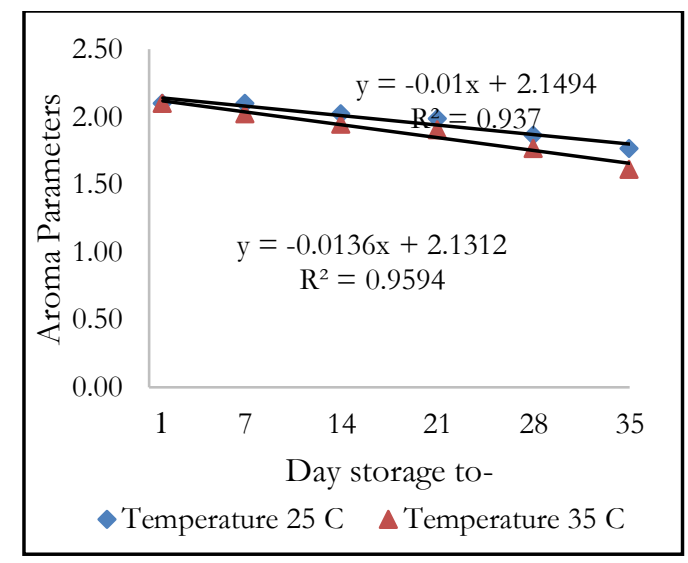

b. Order 1

Figure 3: Graph of the Decrease in the Value of Aroma Against Time

The value of R2 for both temperature order $0(0.9795)$ is greater than order $1(0.9594)$ in the graph of the decrease in the appearance score against time, so order 0 is selected to determine the Arrhenius plot.

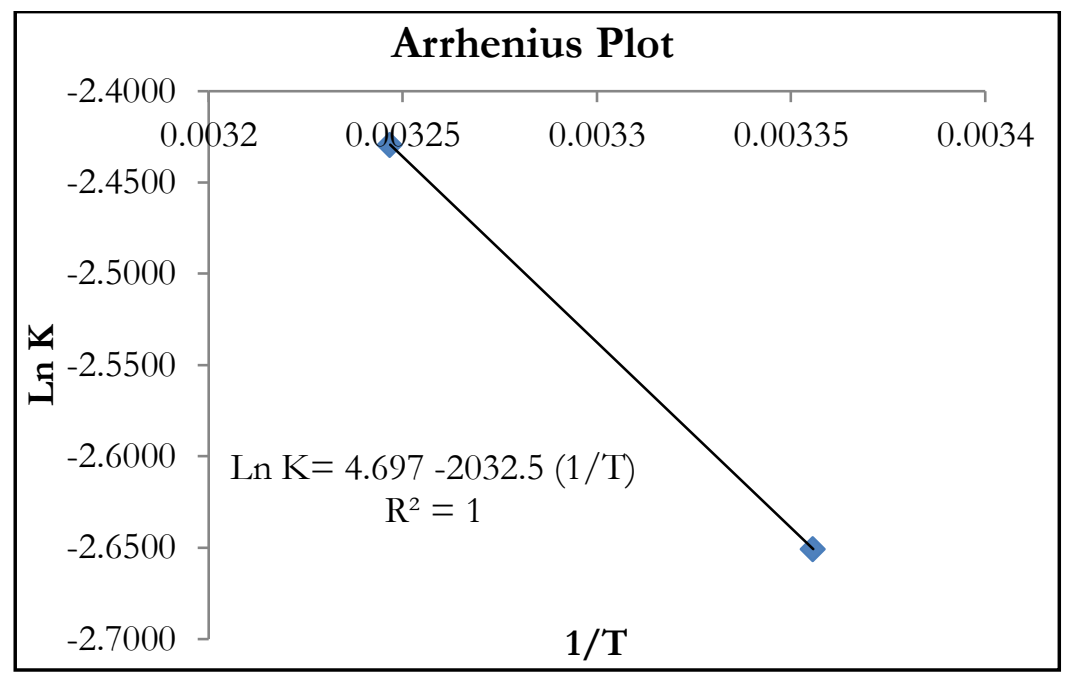

Figure 4: Graph of Arrhenius Plot Parameters of Aroma Nori Gracilaria sp.

Based on the graph of the Arrhenius plot, aroma parameters (Figure 4), the slope value is obtained which is a linear combination of the two temperatures used in storage of nori made from Gracilaria sp. The results of linear regression analysis of the 1/T and $\mathrm{Ln} \mathrm{K}$ plots on the decrease in the aroma produce the plot $\mathrm{Ln} \mathrm{K}=4.697-2032.5(1 / \mathrm{T})$.

\subsubsection{Texture}

The acceptance rate of food products from the nori texture made from Gracilaria sp. is influenced by the moisture content of a product. The texture is a characteristic of a material as a result of a combination of several physical properties including size, shape, quantity and the elements forming the material that can be felt by the sense of touch and taste, including the sense of mouth and sight (Hasany, Afrianto \& Pratama, 2017). 
Table 3: Average Value of the Texture Parameters of Nori from Gracilaria sp.

\begin{tabular}{ccc}
\hline \multirow{2}{*}{ Day Storage To- } & \multicolumn{2}{c}{ Texture Parameters } \\
\cline { 2 - 3 } & $\mathbf{2 5}^{\circ} \mathbf{C}$ & $\mathbf{3 5}^{\mathbf{C}} \mathbf{C}$ \\
\hline 1 & 8.14 & 8.14 \\
7 & 7.57 & 7.29 \\
14 & 7.00 & 6.71 \\
21 & 6.71 & 6.43 \\
28 & 6.43 & 5.86 \\
35 & 5.86 & 5.29 \\
\hline
\end{tabular}

The average value of texture parameters of nori made from Gracilaria sp. (Table 3) which is packaged using aluminum foil shows a decrease in the quality of the texture along with the length of the storage period both at $25 \mathrm{oC}$ and $35 \mathrm{oC}$. The texture of nori as a coating or wrapper for sushi is dominant in a crunchy texture and does not break easily if the nori is still in good quality. The longer and the higher the temperature of the sample is stored, the lower the average score for the scoring test will be. Indirectly, changes in texture are influenced by storage time and storage temperature (Hasany, Afrianto \& Pratama, 2017).

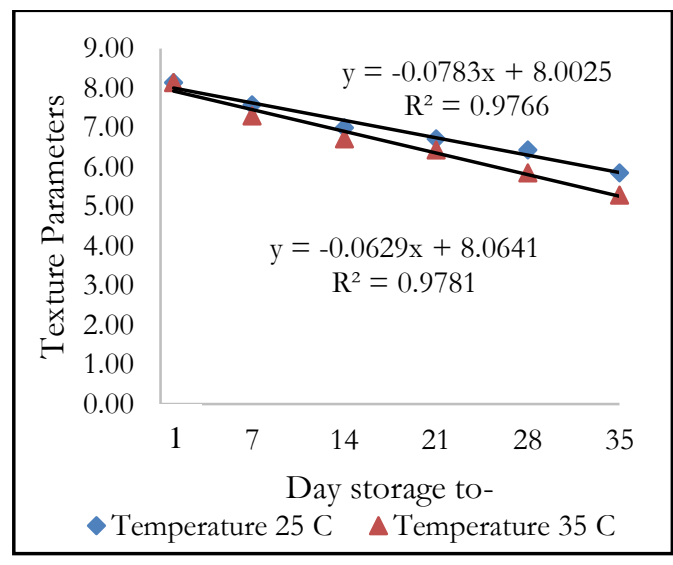

a. Order 0

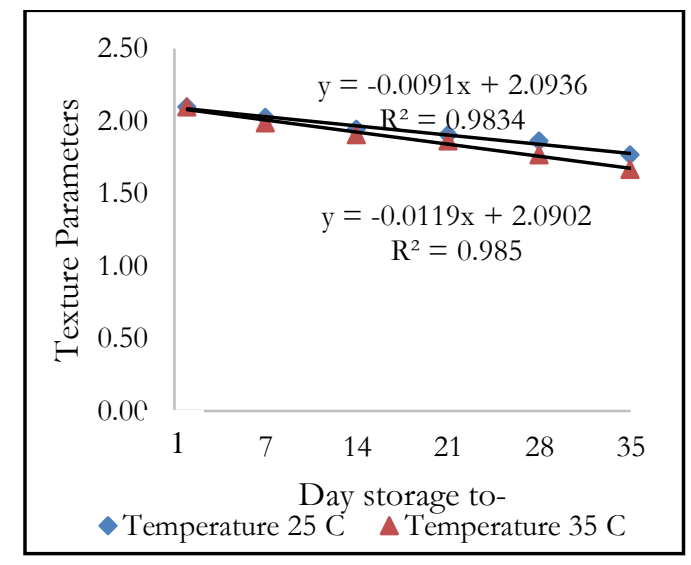

b. Order 1

Figure 5: Graph of the Decrease in Texture Value Against Time

The value of R2 for both temperature order $1(0.985)$ is greater than order $0(0.9781)$ in the graph of the decrease in texture score against time, so order 1 is chosen to determine the Arrhenius plot.

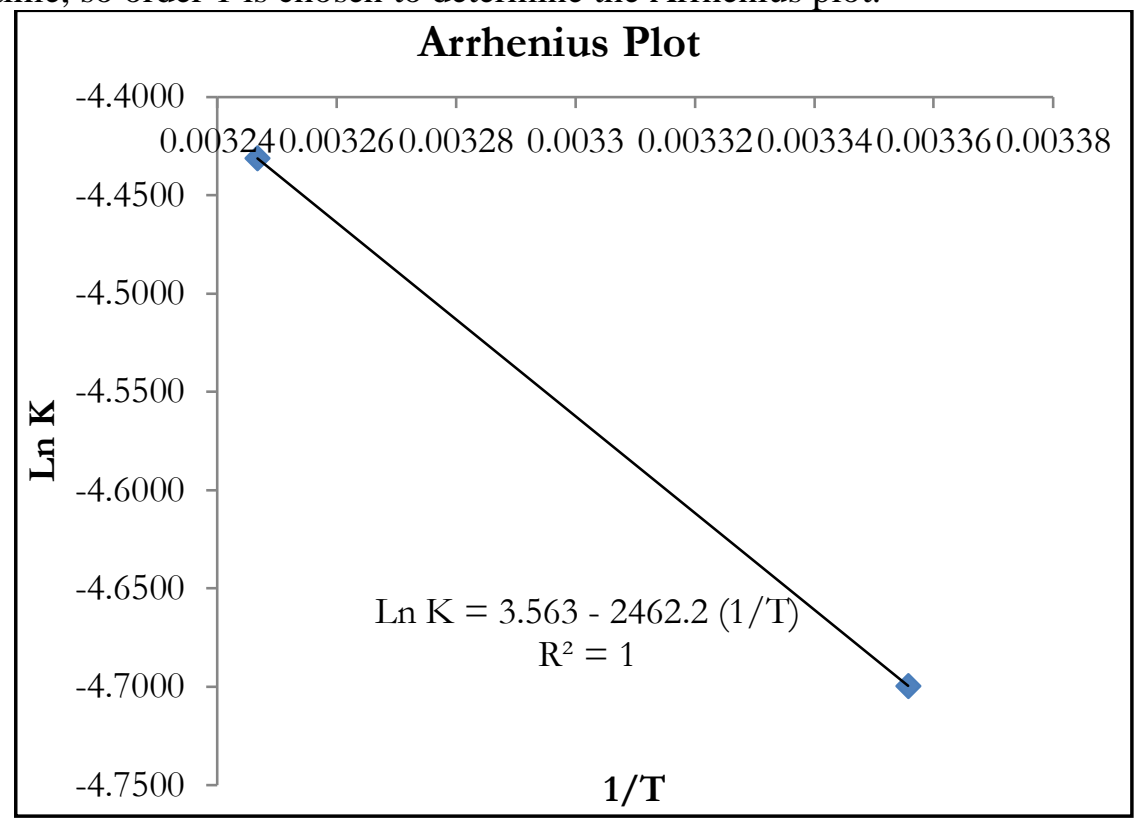

Figure 6: Graph of Arrhenius Plot Texture Parameters for Nori Gracilaria sp.

Based on the graph of the Arrhenius plot, texture parameters (Figure 6), the slope value is obtained which is a linear combination of the two temperatures used in the storage of Nori made from Gracilaria sp. The results of linear 
regression analysis of the 1 / $\mathrm{T}$ and $\mathrm{Ln} \mathrm{K}$ plots on the decrease in the textures result in the plot $\mathrm{Ln} \mathrm{K}=3.563-2462.2$ $(1 / \mathrm{T})$.

\subsubsection{Taste}

Taste is an important factor of food products in addition to the texture, appearance and consistency of ingredients that will affect the taste caused by these food ingredients. The taste of an ingredient can come from the nature of the food itself or because of the presence of other substances added to the processing process (Kartika, Hastuti, \& Supartono, 1988).

Table 4: Average Value of the Taste Parameters of Nori from Gracilaria sp.

\begin{tabular}{ccc}
\hline \multirow{2}{*}{ Day Storage To- } & \multicolumn{2}{c}{ Taste Parameters } \\
\cline { 2 - 3 } & $\mathbf{2 5 ^ { \circ } \mathbf { C }}$ & $\mathbf{3 5}^{\mathbf{}} \mathbf{C}$ \\
\hline 1 & 8.14 & 8.14 \\
7 & 7.86 & 7.29 \\
14 & 7.29 & 7.00 \\
21 & 6.14 & 5.86 \\
28 & 5.86 & 5.57 \\
35 & 5.57 & 5.00 \\
\hline
\end{tabular}

The average value of nori taste parameters made from Gracilaria sp. (Table 4) which was packaged using aluminum foil showed a decrease in taste quality along with the length of the storage period both at $25 \mathrm{oC}$ and $35 \mathrm{oC}$. The decreasing quality of nori made from Gracilaria sp. can be influenced by several factors. These factors are chemical compounds, temperature, concentration, and interactions with other taste components (Tarwendah, 2017).

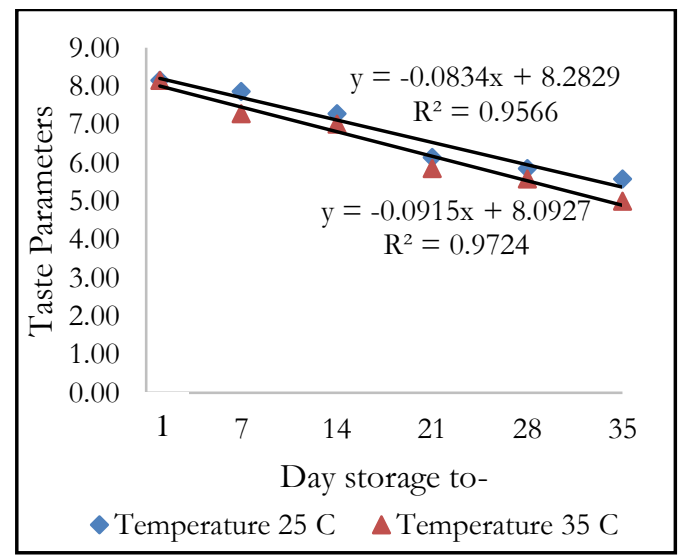

Order 0

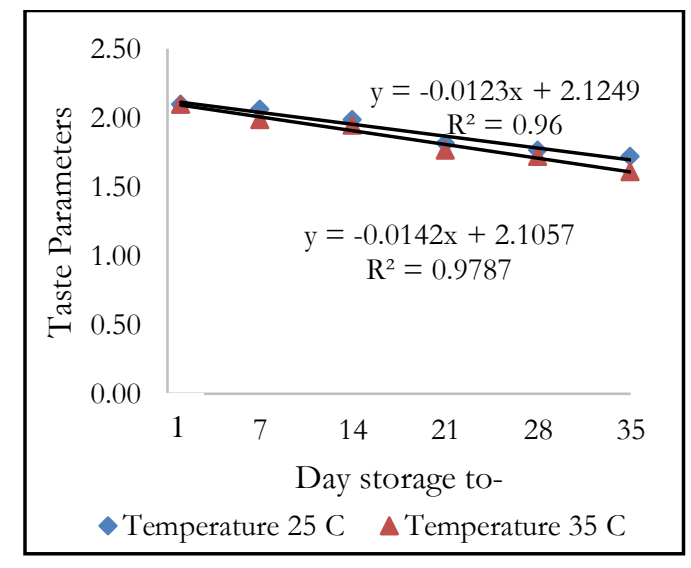

Order 1

Figure 7: Graph of the Relationship of Decreased Sense Value Against Time

The value of $\mathrm{R} 2$ for both temperature order $1(0.9787)$ is greater than order $0(0.9724)$ on the graph of the relationship between the decrease in taste scores against time, so order 1 is chosen to determine the Arrhenius plot. 


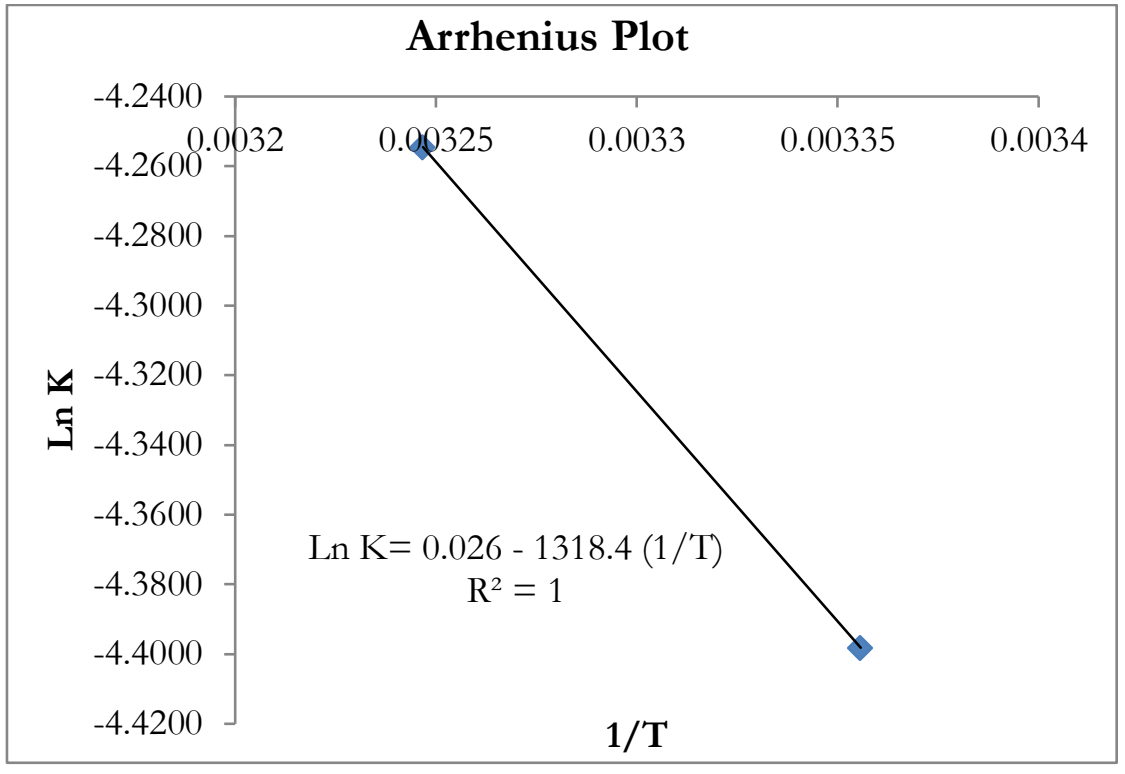

Figure 8: Graph of Arrhenius Plot Parameters for Taste of Nori Gracilaria sp.

Based on the graph of the Arrhenius plot, the taste parameters (Figure 8), the slope value is obtained which is a linear combination of the two temperatures used in the storage of Nori made from Gracilaria sp. The results of linear regression analysis of the $1 / \mathrm{T}$ and $\mathrm{Ln} \mathrm{K}$ plots on the decrease in taste resulted in the plot $\mathrm{Ln} \mathrm{K}=0.026-1318.4(1 / \mathrm{T})$.

\subsection{Water Contents}

The durability of processed products is related to water content because it can affect the development of microorganisms in the product. Testing the moisture content in a food product needs to be determined, because the higher the water content in the food, the more likely it is that the food will spoil and will not last long (Hasany, Afrianto \& Pratama, 2017).

Table 5: Nori Water Content Values from Gracilaria sp.

\begin{tabular}{ccc}
\hline \multirow{2}{*}{ Day Storage To- } & \multicolumn{2}{c}{ Water content $\mathbf{( \% )}$} \\
\cline { 2 - 3 } & $\mathbf{2 5}^{\mathbf{C}} \mathbf{C}$ & $\mathbf{3 5}^{\circ} \mathbf{C}$ \\
\hline 1 & 16.33 & 16.31 \\
7 & 16.50 & 16.44 \\
14 & 16.55 & 16.45 \\
21 & 16.67 & 16.51 \\
28 & 16.74 & 16.53 \\
35 & 16.89 & 16.61 \\
\hline
\end{tabular}

The value of water content of nori made from Gracilaria sp. (Table 5) which was packaged using aluminum foil showed an increase in water content concentration along with the length of the storage period both at $25 \mathrm{oC}$ and $35 \mathrm{oC}$. The increase in water content concentration is caused by high temperature and air velocity that will accelerate the evaporation process on the surface and particle parts due to differences in water vapor pressure. Increasing water content through the absorption of moisture from the environment causes these food products to decline in quality. The value of water content of nori made from Gracilaria sp. there is a range of 15.20 - 17.17\% (Teddy, 2009). 


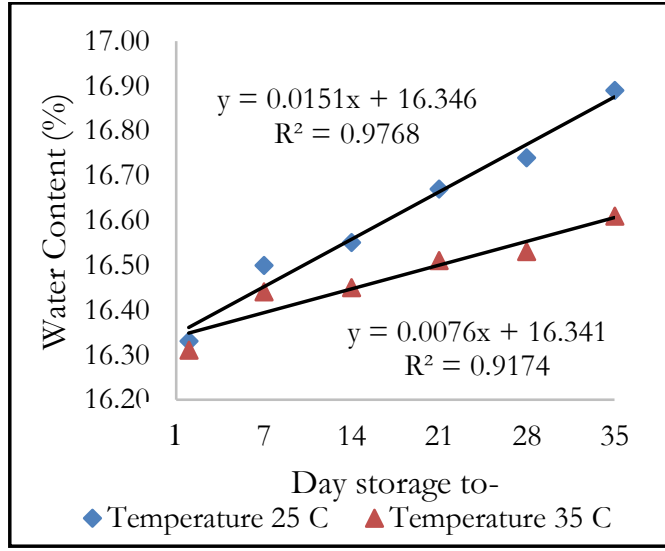

a. Order 0

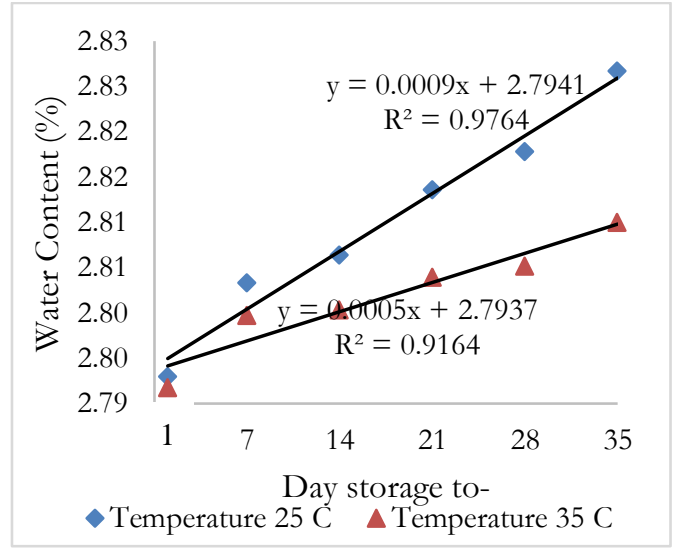

b. Order 1

Figure 9: Graph of Relationship between Increase in Water Content Value Against Time

The value of R2 for both temperature order 0 (0.9768) is greater than order 1 (0.9764) in the graph of the relationship between the decrease in taste score against time, so order 0 is chosen to determine the Arrhenius plot.

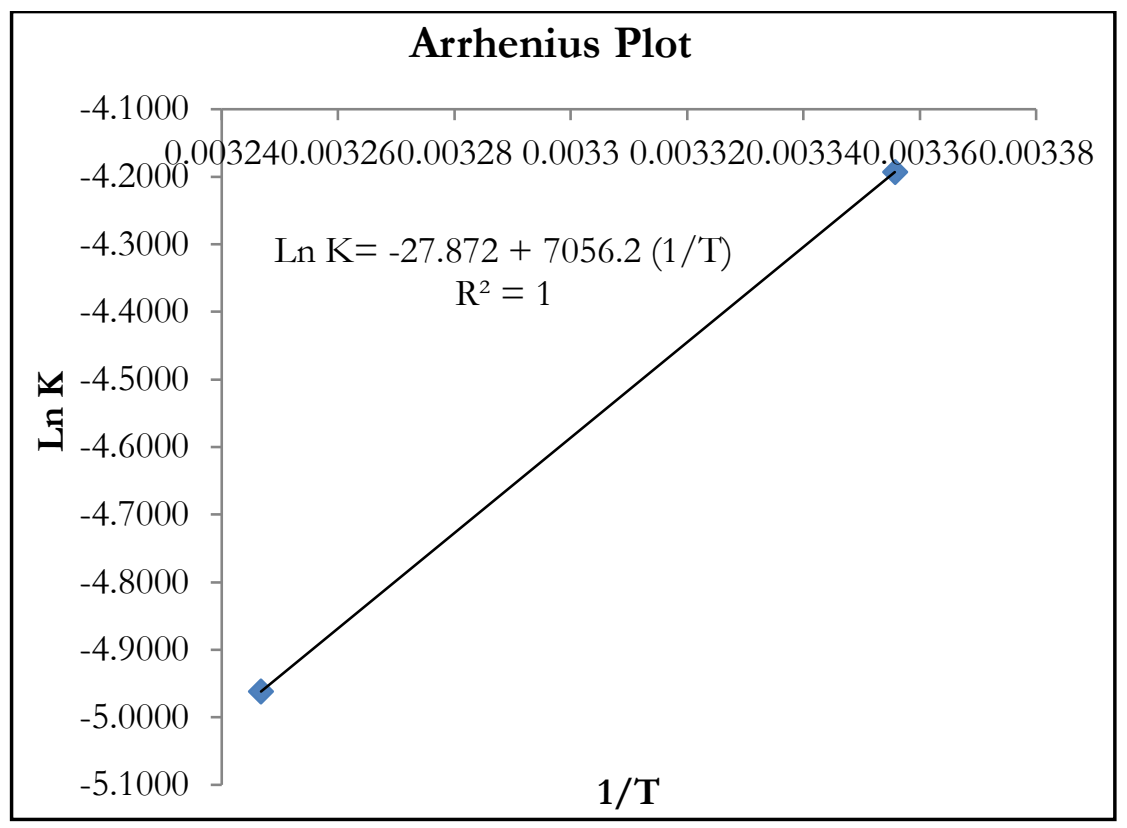

Figure 10: Graph of Arrhenius Plot Water Content of Nori Gracilaria sp.

Based on the graph of the Arrhenius plot water content (Figure 10), the slope value is obtained which is a linear amalgamation of the two temperatures used in the storage of Nori made from Gracilaria sp. The results of linear regression analysis of the $1 / \mathrm{T}$ and $\mathrm{Ln} \mathrm{K}$ plots on the increase in the moisture content resulted in the plot $\mathrm{Ln} \mathrm{K}=27.872$ $+7056.2(1 / \mathrm{T})$.

\subsection{Determination of Shelf Life}

Shelf life is the time until the product experiences a certain level of quality degradation so that it is not fit for consumption or is no longer following the criteria stated on the packaging (the quality is no longer following the quality level promised), due to the deterioration reaction that takes place. The deterioration reaction causes quality degradation and delivers the product to a low-quality condition so that it is not suitable for consumption (Arpah, 2001).

This deterioration reaction will cause changes to the Nori product made from Gracilaria sp. in terms of appearance, aroma, texture, taste and moisture content of the product. Determination of the critical value of nori made from Gracilaria sp. based on the parameter that has the smallest activation energy (Ea). This is following the Arrhenius theory that to produce a product in a chemical reaction, the molecule must have a certain amount of energy to react, or in other words, it can produce product molecules, so the bonds in the reactants must be broken. The breaking of a chemical bond requires energy called the activation energy (Ea) (Pangajow, Gregoria \& Lucia, 2015). The energy 
required by a reaction. A large Ea value indicates that the energy of the interaction between molecules is strong, so starting a reaction requires a large amount of energy.

Table 6: Activation Energy Value (Ea) of Each Parameter

\begin{tabular}{lll}
\hline \multicolumn{1}{c}{ Parameters } & \multicolumn{1}{c}{ Ea (calory /mol) } & \multicolumn{1}{c}{ Arrhenius Plot } \\
\hline Appearance & 2647.68 & Ln K= $1.6714-13325(1 / \mathrm{T})$ \\
Aroma & 4038.58 & Ln $\mathrm{K}=4.1697-2032.5(1 / \mathrm{T})$ \\
Texture & 4892.39 & Ln $\mathrm{K}=3.563-2462.2(1 / \mathrm{T})$ \\
Taste & $\mathbf{2 6 1 9 . 6 6}$ & Ln K $=\mathbf{0 . 0 2 6}-\mathbf{1 3 1 8 . 4}(\mathbf{1} / \mathbf{T})$ \\
Water Content & 14020.67 & Ln K $=-27.872+7056.2(1 / \mathrm{T})$ \\
\hline
\end{tabular}

The results of Ea calculations in table 6 show that the parameter that has the smallest Ea is the taste parameter. After the Ea value is known, the shelf life of Gracilaria sp. can be calculated using the order 1 reaction kinetics, namely Ln $\mathrm{Ct}=\mathrm{Ln} \mathrm{C0}+\mathrm{K} \mathrm{x}$. The shelf life of nori Gracilaria sp. if it is assumed that the temperature during distribution and storage is room temperature $25 \mathrm{oC}$ or $298 \mathrm{~K}$, by using aluminum foil packaging, the shelf life is 89 days 7 hours with the activation energy of changes in the taste parameters of 2619.66 calory $/ \mathrm{mol}$.

Aluminum foil packaging used to store nori Gracilaria sp. is a package composed of hermetic, flexible, and opaque metal so that it has high protective properties against water vapor, light, grease and gas (Aprida, 2017). Aluminum foil packaging has a fairly good moisture and gas resistance and this packaging cannot transmit light and can prevent oxygen from entering the shampooed product (Hendrasty, 2013).

\section{Conclussion}

The shelf life of nori from Gracilaria sp. Stored using aluminum foil packaging at a storage temperature of $250 \mathrm{C}$ or $298 \mathrm{~K}$ is 89 days 7 hours with the activation energy of changes in taste parameters of 2619.66 calory /mol which means that to initiate a change in taste requires energy amounting to 2619.66 calory $/ \mathrm{mol}$.

\section{References}

Abduh, M. S., Maulana, D. A., Tinggi, S., and Trisakti, P. Trial of Red Seaweed (Porphyra) Substitution with Green Grass Jelly Leaves (Cyclea Barbata Miers) in Nori Making. Tourism Scientific Journal. 2018; 23 (3): 231-243.

Aprida, P. D. Estimation of the Shelf Life of Full Cream Powdered Milk Packed with Aluminum Foil (Al7) or Metalized Plastic (Vm-Pet12). Journal of Halal Agroindustry. 2017; 3 (2): 97-104.

Arpah. Determination of Food Product Expiration. Food Science Study Program, Bogor Agricultural University; 2001.

DeMan, M. J. Food Chemistry. Publisher ITB. Bandung; 1997.

Djaeni, M., Prasetyaningrum, A., \& Mahayana, A. Drying Carrageenan from Eucheuma cottonii Seaweed in a Spray Dryer Using Air dehumidified with Natural Zeolite Overview: Product Quality and Energy Efficiency. Momentum. 2012; 8 (2): 28-34.

Hasany, M. R., Afrianto, E., Rusky, D., \& Pratama, I. Estimation of Shelf Life Using the Accelerated Shelf Life Test (ASLT) Method Arrhenius Model on Fruit Nori. Journal of Fisheries and Marine Sciences. 2017; 8 (1): 48-55.

Hendrasty, H. K. Packaging and Storage of Food Materials. Graha Ilmu. Yogyakarta; 2013.

Herawati, H. Determination of the shelf life of food products. Journal of Agricultural Research and Development. $2008 ; 27$ (4): $124-130$.

Kartika, B., Hastuti, P., \& Supartono, W. Guidelines for sensory testing of food ingredients. Gadjah Mada University. Yogyakarta; 1988.

Majid, A., Agustini, T., \& Rianingsih, L. Effect of Differences in Salt Concentration on Sensory Quality and Volatile Compound Content in Anchovy (Stolephorus sp) shrimp paste. Journal of Fisheries Product Processing and Biotechnology. 2014; 3 (2): 17-24.

McHugh, D. A guide to the seaweed industry. FAO fisheries technical paper. 2003; 441.

Nadia, L. Analysis of Water Content of Food Materials. Teaching materials. Jakarta; 2010. 
Pongajow, N.J., Gregoria, S.S. D., and Lucia, C. M. Estimation of the Shelf Life of Halua Kenari Using the Arrhenius Model of Accelerated Shelf Life Testing (ASLT) in Sitaro Islands Smes. Journal of Food Science and Technology. $2015 ; 3$ (2): 36 - 47.

Ramadhan, Y. A., Afrianto, E., Dhahiyat, Y., \& Liviawaty, E. Differences of the way of drying nori from raw seaweed Gracilaria sp, based on the level of preference. Scientific News of the Pacific Region. 2019; 4 (6): 1-11.

Sucipta, I. N., Suriasih, K., and Kenacana, P. K. Packaging, Safe, Efficient, Effective and Efficient Assessment. Udayana University Press. 2017; 1-178.

Suparmi, and Sahri, A. Knowing the Potential of Seaweed: Study of the Utilization of Seaweed Resources from Industrial and Health Aspects. Sultan Agung Journal. 2009; 44 (118): 95-116.

Supriyantini, E., Santosa, G. W., and Alamanda, L. N. Growth of Gracilaria sp. on Media Containing Copper (Cu) with Different Concentrations. Marina Oceanography Bulletin. 2018; 7 (1): 15-21.

Tarwendah, I. P. Review Journal: Comparative Study of Sensory Attributes and Brand Awareness of Food Products. Journal of Food and Agroindustry. 2017; 5 (2): 66-73.

Teddy, M. S. Traditional Nori Making From Glacilaria sp. Aquatic Product Technology. Bogor Agricultural Institute; 2009.

Winarno, F.G. Food chemistry and nutrition. PT Gramedia. Jakarta; 2004. 